\title{
Otolaryngology Surgery in Time of COVID-19-What PPE to Use When?
}

Jian Li Tan, ${ }^{1,3,4_{F A M S}(E N T)}$, Valerie Su-Lin Tay, ${ }^{1,3,4_{F A M S}(E N T)}$, Hao Li $\underline{1,3,4_{F A M S}(E N T)}$, Jin Keat Siow, ${ }^{1,3,4_{F A M S}(E N T)}$, Brenda Sze Peng Ang, ${ }^{2,3,4}$ MMED, MPH, Seng Beng Yeo, ${ }^{1,3,4}$ FAMS (ENT)

Coronavirus disease 2019 (COVID-19), caused by the severe acute respiratory syndrome coronavirus 2 (SARS-CoV-2), was declared a global pandemic by the World Health Organization (WHO) on 11 March $2020 .{ }^{1}$ As otolaryngologists (ENT surgeons) manage various conditions involving the upper airway, they are at particular risk of contracting the disease, especially during performance of procedures on the nose, mouth, pharynx and larynx. We wish to share the policies on personal protective equipment (PPE) instituted by the Department of Otorhinolaryngology, Tan Tock Seng Hospital (TTSH), Singapore in consultation with the National Centre for Infectious Diseases (NCID). NCID is the designated frontline healthcare facility to treat patients with COVID-19 in Singapore. It is physically linked to TTSH, the designated hospital that treated Severe Acute Respiratory Syndrome (SARS) in 2003. Our otolaryngology department provides outpatient and inpatient services to both TTSH (1500 bed capacity) and NCID (330 bed capacity), the largest inpatient healthcare facility in the island nation.

\section{Background}

Our understanding of how SARS-CoV-2 is transmitted is based on our experience from the SARS outbreak in $2003,{ }^{2-3}$ combined with early data from Wuhan, Hubei, People's Republic of China, as well as our present experience with COVID-19.4-6 Based on current information, SARS CoV-2 is transmitted mainly via respiratory droplets. While there is no conclusive evidence of airborne transmission, it is possible that aerosol-generating procedures such as tracheal intubation, can transmit the virus. ${ }^{7,8}$ A recent paper described that aerosolised SARS CoV-2 can last up to 3 hours in the air and even longer on various surfaces. ${ }^{9}$ A point to note is that this study was performed using a Goldberg drum that was not ventilated, and thus may not reflect real world situations. Other possible modes of transmission include contact, fomites and fecal-oral route. ${ }^{10}$

Singapore diagnosed her first case of COVID-19 on 23 January 2020 and reported her first local transmission on 7 February 2020. ${ }^{11,12}$ At the time of writing, we have 25346 confirmed cases with 21 deaths. Anecdotal reports from various countries including China, Italy and Iran have noted that ENT surgeons and ophthalmologists are infected at higher rates as compared to other specialties. ${ }^{13}$ This may be due to the nature of the ENT work and the proximity to the routes of viral transmission. According to an original Chinese press article, this increased rate of infection may be due to the lack of PPE used by both these specialties during the initial outbreak. ${ }^{13}$

As an otolaryngology department providing services to NCID that manages the majority of COVID-19 cases in Singapore, we need to ensure that personal protective measures are well instituted. Transmission of disease from patient to healthcare worker $(\mathrm{HCW})$ or amongst HCWs can rapidly paralyse the healthcare system. After consulting the Department of Infectious Diseases at NCID and studying the best available evidence, we describe below the infection control measures adopted by our department during this pandemic.

\section{Systemic Measures}

In Singapore, the Disease Outbreak Response System Condition (DORSCON) framework is used to guide the country's response to outbreaks. The alert was raised to Orange on 7 February 2020. ${ }^{14}$ National-level measures include border control, contact tracing, social distancing, regular temperature taking and hand hygiene. Hospital-level measures include postponement

\footnotetext{
${ }^{1}$ Department of Otorhinolaryngology, Tan Tock Seng Hospital, Singapore

${ }^{2}$ Department of Infectious Disease, Tan Tock Seng Hospital, Singapore

${ }^{3}$ Yong Loo Lin School of Medicine, National University of Singapore, Singapore

${ }^{4}$ Lee Kong Chian School of Medicine, Nanyang Technological University, Singapore, Imperial College, London, United Kingdom

Address for Correspondence: Dr Tan Jian Li, Department of Otorhinolaryngology, Tan Tock Seng Hospital, 11 Jalan Tan Tock Seng, Singapore 308433

Email: Jian_Li_TAN@ttsh.com.sg
} 
of non-urgent or non-essential surgeries and outpatient appointments, cancellation of non-essential large group meetings, limiting the number of hospital visitors, declaration of travel history and symptoms, and last but not least a moratorium on all vacation leave (local and overseas) for medical staff. Increased frequency of environmental cleaning and decontamination was also instituted across various venues within the hospital, not only the patient care areas but also all common areas. Early studies showed these measures to be effective in removing SARS CoV-2 particles. ${ }^{10}$

In addition, specific measures adopted by the operating theatre (OT) included Level 2 PPE for all personnel performing intubation and extubation, which are considered Aerosol Generating Procedures. Non-participating personnel vacate the OT during these procedures. All OTs in TTSH and NCID use a multitude of engineering features to ensure that air exchanges occur more than 20 times per hour and the air undergoes high-efficiency particulate air (HEPA) filtration. Further details adopted by our OT are similar to what was described in an article published by the anaesthesia departments of Singapore General Hospital and Sengkang General Hospital. ${ }^{15}$
At the time of writing, elective pre-operative testing of COVID-19 has not been recommended in Singapore. One reason could be the need to maximise the impact of testing within a finite capacity. However, as the pandemic appears to be a long-drawn battle, it is possible that pre-operative testing may be done in the future to allow for some resumption of business-as-usual. The Singapore government has recently ramped up the testing capacity, perhaps with this in mind.

\section{Personal Protective Equipment (PPE) Recommendation}

We divide PPE into 3 levels:

Level 1: Surgical mask, eye protection, disposable gloves, gown, surgical cap

Level 2: Fitted N95 mask (National Institute of Occupational Safety and Health (NIOSH)-certified N95 respirators), eye protection, disposable gloves, gown, surgical cap

Level 3: Powered Air-Purifying Respirator (PAPR), eye protection, disposable gloves, gown, surgical cap, shoe covers

Table 1 summarises the recommended levels of PPE per ENT procedure type based on the risk of transmission. The rationale for these recommendations is explained below.

Table 1: Recommended level of personal protective equipment (PPE) per otolaryngology procedure type

\begin{tabular}{|c|c|c|}
\hline Type of procedure & General public & $\begin{array}{c}\text { Patients suspected } * * \text { or } \\
\text { diagnosed with COVID-19 }\end{array}$ \\
\hline Airway procedures & Level 2 & Level 3 \\
\hline Oropharyngeal procedures & Level 2 & Level 3 \\
\hline Sinonasal procedures & Level 2 & Level 3 \\
\hline Otological procedures that do not require drilling & Level 1 & Level 2 \\
\hline Head and neck procedures that require access of the upper aerodigestive tract* & Level 2 & Level 3 \\
\hline Head and neck procedures that do not require access of the upper aerodigestive tract & Level 1 & Level 2 \\
\hline \multicolumn{3}{|c|}{$\begin{array}{l}\text { Level } 1 \text { - Surgical mask, eye protection, disposable gloves, gown and surgical cap } \\
\text { Level } 2 \text { - Fitted N95 mask (National Institute of Occupational Safety and Health (NOISH)-certified N95 respirators), eye protection, disposable gloves, } \\
\text { gown, surgical cap } \\
\text { Level } 3 \text { - Powered Air-Purifying Respiratory (PAPR), eye protection, disposable gloves, gown, surgical cap, shoe covers }\end{array}$} \\
\hline \multicolumn{3}{|c|}{$\begin{array}{l}\text { *Upper aerodigestive tract refers to nasal cavity, oral cavity, nasopharynx, oropharynx, hypopharynx, larynx and cervical trachea } \\
\text { **A suspected patient is defined by the Ministry of Health, Singapore based on the presence of acute respiratory symptoms or infective changes on chest } \\
\text { imaging, in association with travel outside of Singapore or to hotspots of COVID-19 outbreak in Singapore, or contact with a confirmed COVID-19 } \\
\text { patient. The exact details of this definition evolve according to the epidemiology of COVID-19 in Singapore. The reader may refer to www.moh.gov.sg } \\
\text { for information. }\end{array}$} \\
\hline
\end{tabular}




\section{Procedures Performed in OT Under General Anaesthesia}

\section{Airway Procedures}

Recommendation: Level 2 PPE for general public, Level 3 PPE for patients suspected or diagnosed with COVID-19

Examples of airway procedures performed in the OT are tracheostomy, endolaryngeal microsurgery and laryngoscopy. These procedures, especially tracheostomy, are considered by the World Health Organization as Aerosol Generating Procedures (AGP). ${ }^{17}$ We recommend Level 2 PPE because it significantly reduces the risk of transmission of SARS to HCWs during AGP. ${ }^{18}$ However, if a patient is confirmed or suspected of having COVID-19 (based on Singapore Ministry of Health's definition which changes as the pandemic evolves) and requires urgent surgery, we advise Level 3 PPE for additional precaution. Certain techniques such as complete apnoea during insertion of the tracheostomy tube can be employed to further decrease the risk of viral transmission through reducing the amount of aerosol generation. The British Laryngological Association has also recommended that intubation be preferred over jet ventilation. ${ }^{19}$ Similarly, in our unit, we avoided jet ventilation and considered a surgical airway as an alternative if access to a challenging airway is required during this pandemic.

\section{Oropharyngeal Procedures}

Recommendation: Level 2 PPE for general public, Level 3 PPE for patients suspected or diagnosed with COVID-19

Tonsillectomy, palate and tongue base surgeries are performed in this anatomical region. These are considered as potentially aerosol generating. Therefore, our recommendation is Level 2 PPE. Given the nature of the surgeries in this category, it is unlikely that they will need to be done urgently in a COVID-19 case. If an unexpectedly urgent oropharyngeal surgery becomes indicated in a confirmed or suspected COVID-19 patient, the procedure should be performed with Level 3 PPE.

\section{Otological Procedures}

Recommendation: Level 2 PPE for the general public if drilling is involved, Level 1 if no drilling. Level 3 PPE for patients suspected or diagnosed with COVID-19 if drilling is involved, Level 2 if no drilling
Otological procedures such as tympanoplasty and mastoidectomy involve cutting and suctioning within the enclosed middle ear and drilling of mastoid air cells. Mastoid air cells contain respiratory columnar epithelium. ${ }^{20}$ To our knowledge, there are no studies to confirm the presence of SARS CoV-2 virus particles in the mastoid despite the presence of respiratory epithelium. However, drilling of the mastoid bone can result in aerosolisation around the operative field, increasing the risk of transmission. This is differentiated from nasal endoscopic drilling where drilling and suctioning occur within a relatively enclosed space. Therefore, our recommendation is Level 2 PPE if drilling is involved and Level 1 PPE if no drilling involved, for example in a myringoplasty. The level of PPE should be increased by 1 if the operation is performed on a suspected or confirmed COVID-19 patient.

\section{Sinonasal Procedures}

Recommendation: Level 2 PPE for the general public, Level 3 PPE for patients suspected or diagnosed with COVID-19

Examples of sinonasal procedures are septoplasty, inferior turbinoplasties, Functional Endoscopic Sinus Surgery (FESS) and endonasal skull base surgeries such as transphenoidal resection of pituitary adenomas. These are procedures involving cutting, debriding, suctioning of mucosa and bone within an enclosed cavity. There is uncertainty surrounding the optimal PPE for sinonasal procedures. A commentary recently published by Stanford University School of Medicine, based on information from anecdotal reports and personal correspondence from various international colleagues, highlighted that N95 masks might not be sufficient in preventing the transmission of COVID-19 and that endoscopic nasal surgery has the highest risk of spreading the infection. ${ }^{21}$ However, a team of neurosurgeons from Wuhan suggested that the transmission of COVID-19 to HCWs from a patient who underwent endonasal endoscopic pituitary adenoma resection that occurred post-operatively, was attributed to insufficient personal airway protection. ${ }^{22}$

The Stanford commentary also mentioned that a neurosurgeon in Wuhan stated N95 masks alone were insufficient in preventing the transmission of COVID-19 to HCWs, and the situation only improved after the use of PAPR. However, N95 masks have been shown to effectively prevent transmission of SARS to $\mathrm{HCW},{ }^{23,24}$ and the N95 respirator is only one component of the PPE. Other measures such as the technique of donning 
and doffing a PPE to avoid self-contamination, and environmental decontamination, ${ }^{10}$ are equally important. Prolonged usage of the same PPE may also reduce its effectiveness.

On the other hand, the same commentary ${ }^{21}$ also mentioned that the viral load is higher in nasal samples compared to throat samples. This is concerning because powered instruments such as microdebriders or endoscopic drills are often used during sinonasal procedures, and may result in aerosolisation. However, a recent study from Boston showed that microdebriders did not cause aerosolisation, in contrast to endoscopic drills. ${ }^{25}$ Furthermore, the use of these instruments takes place within the relatively enclosed sinonasal cavity. With closed-circuit suction available, aerosolisation may be limited as compared to that in an open cavity.

When considering PPE recommendations by various guidelines, there is a significant country-to-country variation in disease burden, community spread, systemic and hospital protective equipment, and availability of COVID-19 testing capability. Based on the evidence that is currently available, we recommend that Level 2 PPE is adequate when performing sinonasal procedures on the general public. Furthermore, with systemic infection control measures in place at the level of the hospital and the community, as well as the fact that sinonasal procedures are performed endoscopically within an enclosed cavity, there is a possibility that Level 1 PPE may be sufficient for such surgeries on the general public. However, until more evidence emerges, escalation of PPE to Level 3 is recommended when performing sinonasal procedures on patients diagnosed with or suspected to have COVID-19, in order to minimise the risk of viral transmission to HCWs.

\section{Head and Neck Procedures not Requiring Access of the Upper Aerodigestive Tract}

Recommendations: Level 1 PPE for the general public, Level 2 PPE for patients suspected or diagnosed with COVID-19

The upper aerodigestive tract refers to the nasal cavity, oral cavity, nasopharynx, oropharynx, hypopharynx, larynx and cervical trachea. Head and neck procedures such as thyroidectomy, parotidectomy and neck dissection, do not require access through these sites. Thus, Level 1 PPE should suffice after intubation. Level 2 PPE is recommended in patients diagnosed with or suspected to have COVID-19 to minimise the risk of transmission to HCWs. Of note, the use of energy devices that vaporises tissue should be discouraged as it can potentially aerosolise viral particles that may be present in the patient's bloodstream. Viremia was detected in SARS patients, ${ }^{26,27}$ which is also caused by a coronavirus, raising the possibility of viremia in COVID-19 patients.

\section{Head and Neck Procedures Requiring Access of the Upper Aerodigestive Tract}

Recommendations: Level 2 PPE for the general public, Level 3 PPE for patients suspected or diagnosed with COVID-19

These procedures include maxillectomy, glossectomy, mandibulectomy, nasopharyngectomy, oropharyngectomy, hypopharyngectomy, laryngectomy and laryngopharyngectomy. The HCWs involved face prolonged risk of exposure to respiratory aerosol and should be well protected. We recommend Level 2 PPE when operating on the general public and Level 3 PPE when operating on patients suspected or diagnosed with COVID-19, consistent with our recommendations above for site-specific procedures.

\section{Eye Protection}

The conjunctiva may be potential portals of infection. ${ }^{16}$ The definition of eye protection may vary from safety glasses to face shields to air-tight goggles. There is insufficient evidence regarding their relative superiority. However, in procedures with a high risk of splash or aerosolisation, air-tight goggles can be considered.

\section{Outpatient Clinic Procedures}

Since a variety of outpatient procedures performed in the otorhinolaryngology clinics have a high risk of aerosolisation, we recommend deferring all non-urgent high-risk procedures during a pandemic. But if such procedures become essential for patient care, appropriate PPE should be worn.

Flexible nasolaryngoscopy, stroboscopy and related procedures such as injection medialisation and tracheostomy tube change are considered high risk procedures. If the procedure cannot be deferred, it should be performed with Level 2 PPE in a designated room which can be subsequently decontaminated. This room should have air ventilation systems and HEPA filters similar to that of the OTs. Diagnostic rigid nasoendoscopy, and associated procedures such as 
topical anaesthetic spray, nasal biopsy or intervention can be performed with Level 2 PPE. Aural toilet and other otological procedures such as myringotomy and grommet tube insertion can be performed using Level 1 PPE. However, as the cough reflex may be triggered during such procedures, a surgical mask for the patient to wear is advised.

\section{Ancillary Measures}

Proper fitting of N95 masks, the correct use and disposal of PPE and meticulous hand hygiene are also crucial in infection control.

\section{Conclusion}

In a pandemic, situations evolve quickly, and each country's healthcare system will face its unique set of challenges and limitations. The level of available evidence regarding the appropriate PPE against COVID-19 for various ENT procedures is still low. Our recommendations are formulated based on the setup and resources available to our unit at TTSH and NCID as well as currently available evidence. Our recommendations cannot be taken in isolation without considering the overall load and containment of the disease in the community, the availability of PPE for all HCWs in the country, and training of HCWs in the correct use and safe disposal of PPE. We are heartened that the global medical fraternity is banding together to fight this scourge upon its people. Rapid communications are important for us to review and change our practices so as to better protect our colleagues and patients.

\section{Acknowledgement}

We would like to thank Dr David Lye Chien Boon, senior consultant, infectious disease physician in NCID, for guiding us in the preparation of this manuscript, Dr Kan Kum Chuen, Roy, senior consultant anaesthesiologist in TTSH, for providing information on the infection control measures adopted by our operating theatres, and the ENT surgeons in TTSH for endorsing the PPE recommendations made in this paper.

\section{REFERENCES}

1. World Health Organization. Emergencies press conference on coronavirus disease outbreak - 11 March 2020. Available at: https://www.who.int/docs/default-source/coronaviruse/transcripts/ who-audio-emergencies-coronavirus-press-conference-full-and-final11 mar2020.pdf?sfvrsn=cb432bb3_2. Accessed on 11 May 2020.

2. Chen M, Leo YS, Ang B, Heng BH, Choo P. The outbreak of SARS at Tan Tock Seng Hospital - relating epidemiology to control. Ann Acad Med Singapore 2006;35:317-25.
3. Goh KT, Cutter J, Heng BH, Ma S, Koh BK, Kwok C, et al. Epidemiology and control of SARS in Singapore. Ann Acad Med Singapore 2006;35:301-16.

4. Young BE, Ong SWX, Kalimuddin S, Low JG, Tan SY, Loh J, et al. Epidemiologic features and clinical course of patients infected with SARS-CoV-2 in Singapore. JAMA 2020;323:1488-94. Erratum in: DOI: $10.1001 /$ jama.2020.4372

5. Li Q, Guan X, Wu P, Wang X, Zhou L, Tong Y, et al. Early transmission dynamics in Wuhan, China, of novel coronavirus-infected pneumonia. N Engl J Med 2020; 382:1199-1207.

6. Poutanen SM, McGeer AJ. Transmission and control of SARS. Curr Infect Dis Rep, 2004; 6:220-7.

7. Scales DC, Green K, Chan AK, Poutanen SM, Foster D, Nowak K, et al. Illness in intensive care staff after brief exposure to severe acute respiratory syndrome. Emerg Infect Dis 2003;9:1205-10.

8. Christian MD, Loutfy M, McDonald LC, Martinez KF, Ofner M, Wong $\mathrm{T}$, et al. Possible SARS coronavirus transmission during cardiopulmonary resuscitation. Emerg Infect Dis 2004;10:287-93.

9. van Doremalen N, Bushmaker T, Holbrook MG, Gamble A, Williamson BN, Tamin A, et al, Aerosol and surface stability of SARS-CoV-2 as compared with SARS-CoV-1. N Engl J Med 2020;382:1564-7.

10. Ong SWX, Tan YK, Chia PY, Lee TH, Ng OT, Wong MSY, et al. Air, surface environmental, and personal protective equipment contamination by severe acute respiratory syndrome coronavirus 2 (SARS-CoV-2) from a symptomatic patient. JAMA 2020; 323:1610-2.

11. Ministry of Health, Singapore. Three more confirmed cases of novel coronavirus infection in Singapore. Available at: https://www.moh.gov.sg/news-highlights/details/three-moreconfirmed-cases-of-novel-coronavirus-infection-in-singapore. Accessed on 11 May 2020.

12. Hsu LY, Chia PY, Lim JF. The novel coronavirus (SARS-CoV-2) epidemic. Ann Acad Med Singapore 2020;49:105-7.

13. Bloomberg. Europe's doctors repeat errors made in Wuhan, China medics say. Bloomberg news, 17 March 2020. Available at: https://www.bloomberg.com/news/articles/2020-03-17/europe-sdoctors-getting-sick-like-in-wuhan-chinese-doctors-say. Accessed on 11 May 2020.

14. Ministry of Health, Singapore. Risk assessment raised to orange. Available at: https://www.moh.gov.sg/news-highlights/details/riskassessment-raised-to-dorscon-orange. Accessed on 11 May 2020.

15. Wong J, Goh QY, Tan Z, Lie SA, Tay YC, Ng SY, et al. Preparing for a COVID-19 pandemic: a review of operating room outbreak response measures in a large tertiary hospital in Singapore. Can J Anaesth 2020;67:732-45.

16. Hui KPY, Cheung MC, Perera RAPM, Ng KC, Bui CHT, Ho JCW, et al. Tropism, replication competence, and innate immune responses of the coronavirus SARS-CoV-2 in human respiratory tract and conjunctiva: an analysis in ex-vivo and in-vitro cultures. Lancet Respir Med 2020; S2213-2600(20)30193-4.

17. World Health Organization. Rational use of personal protective equipment for coronavirus disease 2019 (COVID-19) Interim guidance. Available at: https://apps.who.int/iris/bitstream/ handle/10665/331215/WHO-2019-nCov-IPCPPE_use-2020.1-eng. pdf; Accessed on 11 May 2020. 
18. Loeb M, McGeer A, Henry B, Ofner M, Rose D, Hlywka T, et al. SARS among critical care nurses, Toronto. Emerg Infect Dis 2004;10:251-5.

19. British Laryngological Association. Updated and amended message from the BLA President, Mark Watson. Available at: http://www.britishlaryngological.org/news/amended-bla-message-andstatement-president-mark-watson. Accessed 11 May 2020.

20. Henatsch D, Alsulami S, Duijvestijn AM, Cleutjens JP, Peutz-Kootstra CJ, Stokroos RJ. Histopathological and inflammatory features of chronically discharging open mastoid cavities: Secondary analysis of a randomized clinical trial. JAMA Otolaryngol Head Neck Surg 2018;144:211-7.

21. ENTtoday. Otolaryngologists may contract COVID-19 during surgery.Available at: https://www.enttoday.org/article/otolaryngologistsmay-contract-covid-19-during-surgery/. Accessed 11 May 2020.

22. Zhu W, Huang X, Zhao H, Jiang X. A COVID-19 Patient Who Underwent Endonasal Endoscopic Pituitary Adenoma Resection: A Case Report, Neurosurgery 2020; DOI: 10.1093/neuros/nyaa147

23. Seto WH, Tsang D, Yung RW, Ching TY, Ng TK, Ho M, et al. Effectiveness of precautions against droplets and contact in prevention of nosocomial transmission of severe acute respiratory syndrome (SARS). Lancet 2003;361(9368):1519-20.

24. Centers for Disease Control and Prevention. Respirator Fact Sheet. Available at: https://www.cdc.gov/niosh/npptl/topics/respirators/ factsheets/respsars.html. Accessed on 11 May 2020.

25. Workman AD, Welling DB, Carter BS, Curry WT, Holbrook EH, Gray ST, et al. Endonasal instrumentation and aerosolization risk in the era of COVID-19: simulation, literature review, and proposed mitigation strategies. Int Forum Allergy Rhinol 2020; DOI: 10.1002/ alr.22577.

26. Wang WK, Fang CT, Chen HL, Yang CF, Chen YC, Chen ML, et al. Detection of severe acute respiratory syndrome coronavirus RNA in plasma during the course of infection. J Clin Microbiol 2005;43:962-5.

27. Chen W, Xu Z, Mu J, Yang L, Gan H, Mu F, et al. Antibody response and viraemia during the course of severe acute respiratory syndrome (SARS)-associated coronavirus infection. J Med Microbiol 2004;53(Pt 5):435-438. 